\title{
Determination of adsorption and kinetic parameters for methyl acetate esterification and hydrolysis reaction catalyzed by Amberlyst 15
}

\author{
Weifang Yu, K. Hidajat, Ajay K. Ray* \\ Department of Chemical and Environmental Engineering, The National University of Singapore, \\ 10 Kent Ridge Crescent, Singapore 119260, Singapore
}

Received 1 March 2003; received in revised form 8 October 2003; accepted 18 October 2003

\begin{abstract}
In this paper, the adsorption equilibrium constants, dispersion coefficients, and kinetic parameters were obtained for the liquid phase reversible reaction of methanol with acetic acid catalyzed by Amberlyst 15. The adsorption and kinetic parameters are determined corresponding to two different mobile phases, methanol and water. Such parameters are required for three different applications of the model reaction: namely, synthesis of methyl acetate, removal of dilute acetic acid from wastewater, and hydrolysis of methyl acetate. Experiments were conducted in a packed bed reactor in the temperature range 313-323 K using a rectangular pulse input. A mathematical model for a quasi-homogeneous kinetics was developed. The adsorption and kinetic parameters together with their dependence on temperature were determined by tuning the simulation results to fit the experimentally measured breakthrough curves of acetic acid, water (or methanol) and methyl acetate using a state-of-the-art optimization technique, the genetic algorithm. The mathematical model was further validated using the tuned parameters to predict experimental results at different feed concentrations and flow rates. The kinetics reported in this study was obtained under conditions free of both external and internal mass transfer resistance. The computed parameters were found to predict experimental elution profiles for both batch and plug flow reactors reasonably well.
\end{abstract}

(c) 2003 Elsevier B.V. All rights reserved.

Keywords: Methyl acetate; Adsorption parameters; Kinetic constants; Amberlyst 15; Direct synthesis; Esterification; Hydrolysis; Genetic algorithm

\section{Introduction}

Methyl acetate synthesis by esterification of acetic acid with methanol and the backward reaction, the hydrolysis of methyl acetate, have been considered as model reactions for reactive distillation [1] and simulated moving bed (SMB) reactor [2]. Methyl acetate is used as solvent for the production of coating materials, nitro-cellulose, cellulose acetate, cellulose ethers, and celluloid. It is also used with a wide variety of resins, plasticizers, lacquers and certain fats. Methyl acetate (MeOAc) is produced by the liquid-phase reactioin of acetic acid (HOAc) and methanol $(\mathrm{MeOH})$ catalyzed by sulphuric acid or a sulphonic acid ion-exchange resin in the temperature range of 310-325 K and at atmospheric pressure. The reaction is

$$
\mathrm{CH}_{3} \mathrm{COOH}+\mathrm{CH}_{3} \mathrm{OH} \rightleftharpoons \mathrm{CH}_{3} \mathrm{COOCH}_{3}+\mathrm{H}_{2} \mathrm{O}
$$

\footnotetext{
* Corresponding author. Tel: +65-6874-8049; fax: +65-6779-1936.

E-mail address: cheakr@nus.edu.sg (A.K. Ray).
}

The hydrolysis of methyl acetate is also of importance because, in the synthesis of polyvinyl alcohol, methyl acetate is formed as byproduct, and acetic acid and methanol can be recycled in the process [3]. In addition to the synthesis $[1,2]$ and hydrolysis of methyl acetate [4], the above reaction finds application in the recovery of dilute acetic acid from wastewater, particularly in processes involving acetic anhydride $[5,6]$ in which the dilute acetic acid should be removed before discharging the wastewater. In the latter, methanol is added to convert acetic acid to methyl acetate, which can be recovered easily from water. In this case, the synthesis reaction takes place in the presence of excess water instead of excess methanol as used for normal ester synthesis. Reactive distillation [7-9] has been found to be suitable for the methyl acetate reaction system for the three different processes mentioned above, namely, synthesis and hydrolysis of methyl acetate and recovery of acetic acid. Like reactive distillation, SMB technology [2] can provide economic benefit for the above reversible reaction. In-situ separation of the products at the site of chemical reaction in the SMB reactor (SMBR) facilitates the reversible reaction 


\begin{tabular}{|c|c|}
\hline \multicolumn{2}{|c|}{ Nomenclature } \\
\hline A & acetic acid \\
\hline$C$ & liquid phase concentration (mol/l) \\
\hline$D$ & apparent axial dispersion coefficient $\left(\mathrm{m}^{2} / \mathrm{s}\right)$ \\
\hline $\mathrm{E}, E$ & methyl acetate, activation energy (kJ/mol) \\
\hline$\vec{F}$ & objective function $\left(\mathrm{mol}^{2} / \mathrm{l}^{2}\right)$ \\
\hline$\Delta G^{\circ}$ & change in Gibbs free energy $(\mathrm{kJ} / \mathrm{mol})$ \\
\hline$\vec{H}$ & height equivalent theoretical plate (m) \\
\hline$\Delta H^{\circ}$ & change in enthalpy $(\mathrm{kJ} / \mathrm{mol})$ \\
\hline HOAc & acetic acid \\
\hline$k$ & reaction rate constant $\left(\mathrm{s}^{-1}, 1 / \mathrm{mol} \mathrm{s}\right)$ \\
\hline K & $\begin{array}{l}\text { equilibrium constant (adsorption or reaction) } \\
(1 / \mathrm{mol})\end{array}$ \\
\hline$L$ & length of the packed bed reactor $(\mathrm{m})$ \\
\hline M & methanol \\
\hline $\mathrm{MeOAc}$ & methyl acetate \\
\hline $\mathrm{MeOH}$ & methanol \\
\hline$N$ & number of theoretical plates \\
\hline$P$ & purity \\
\hline$q$ & concentration in polymer phase $(\mathrm{mol} / \mathrm{l})$ \\
\hline$r$ & reaction rate $(\mathrm{mol} / \mathrm{ls})$ \\
\hline$R$ & radius, gas constant $(\mathrm{m}, \mathrm{J} / \mathrm{mol} \mathrm{K})$ \\
\hline$\Delta S^{\circ}$ & change in entropy $(\mathrm{J} / \mathrm{mol} \mathrm{K})$ \\
\hline$t$ & time $(\min )$ \\
\hline$T$ & temperature $(\mathrm{K})$ \\
\hline$u$ & superficial fluid phase flow rate $(\mathrm{cm} / \mathrm{min})$ \\
\hline$w$ & weight fraction \\
\hline $\mathrm{W}, W$ & water, weight $(\mathrm{g})$ \\
\hline$x, X$ & vector of fitted parameters, conversion \\
\hline$Y$ & yield \\
\hline$z$ & axial coordinate \\
\hline \multicolumn{2}{|c|}{ Greek letters } \\
\hline$\varepsilon$ & void fraction \\
\hline$v$ & stoichiometric coefficient of component \\
\hline$\rho$ & density \\
\hline \multicolumn{2}{|c|}{ Subscripts } \\
\hline ap & apparent \\
\hline A & acetic acid \\
\hline $\mathrm{b}$ & backward \\
\hline e & equilibrium \\
\hline $\exp$ & experiment \\
\hline $\mathrm{E}$ & methyl acetate \\
\hline $\mathrm{f}$ & feed, forward \\
\hline $\mathrm{h}$ & hydrolysis \\
\hline$i$ & component $i(\mathrm{~A}, \mathrm{E}, \mathrm{M}$ or $\mathrm{W})$ \\
\hline$j$ & data point, $j$ th application \\
\hline$k$ & mobile phase (M or $\mathrm{W})$ \\
\hline $\mathrm{m}$ & model, number of data points \\
\hline M & methanol \\
\hline $\mathrm{p}$ & width of rectangular pulse \\
\hline $\mathrm{r}$ & recovery \\
\hline $\mathrm{R}$ & reaction \\
\hline
\end{tabular}

\begin{tabular}{|ll|}
\hline S & synthesis \\
$\mathrm{W}$ & water \\
\multicolumn{3}{|c|}{ Superscript } \\
0 & initial \\
\hline
\end{tabular}

to completion beyond thermodynamic equilibrium and at the same time obtaining products of high purity. SMBR [10-15] has recently received growing interest as an alternative for reactive distillation, especially in some fine chemical and pharmaceutical applications when the chemical species involved in the process are non-volatile or temperature sensitive. In order to investigate the performance of the SMBR for the above three different applications of the model reaction (Eq. (1)) catalyzed by ion exchange resin (Amberlyst 15), methanol or water has to be used as mobile phase depending on the applications. In this work, the adsorption equilibrium constants, dispersion coefficients and kinetic parameters have been determined for the three different application processes of the methyl acetate reaction system, corresponding to the different mobile phases, methanol or water.

\section{Reaction kinetics and adsorption isotherm}

Most reactions catalyzed by ion exchange resins can be classified either as quasi-homogeneous or as quasiheterogeneous. The kinetics of this model reaction catalyzed by Amberlyst 15 has also been described in past investigations both with a quasi-homogeneous and a quasiheterogeneous model. $\mathrm{Xu}$ and Chuang [6] deduced a kinetic equation in the form of a power law model from the Langmuir-Hinshelwood model for the methyl acetate system, by assuming that the adsorption is weak for all the components. They concluded that, although the resin is not completely swollen and the active polymer-bound group $\left(-\mathrm{SO}_{3} \mathrm{H}\right)$ is not totally dissociated from the carrier, the reaction can still be considered as homogeneous as long as all the chemicals involved in the process are weakly adsorbed. Mazzotti et al. [13] proposed a quasihomogeneous kinetic model for a similar reaction system, esterification of acetic acid to ethyl acetate in the presence of Amberlyst 15 ion exchange resin catalyst. They assumed that the reaction occurs only in the polymer phase, and that the bulk liquid and polymer phases are in constant equilibrium conditions. Instead of calculating the concentrations of adsorbed components by the Langmuir type adsorption isotherm, they used a phase equilibrium model by equating the activities of the involved components in both liquid and polymer phases to relate the component concentrations in the polymer phase to those in the bulk liquid phase. The activities were estimated using UNIFAC for the liquid phase and the extended Flory-Huggins model for the polymer phase. The parameters were fitted to the 
adsorption equilibrium experimental results of four binary systems where no reactions were involved. However, their phase equilibrium model is impractical for most adsorption systems, since non-reactive binary mixtures are scarce. The model also involves complexity and inconvenience in computation. Hence, their method is not suitable in predicting a phase equilibrium of reacting system and is not used in the present study. Song et al. [16] developed a heterogeneous Langmuir-Hinshelwood-Hougen-Watson (LHHW) type reaction rate model for the synthesis of methyl acetate. They considered that adsorption effects must be taken into account to describe the reaction catalyzed by ion exchange resins, because more than $95 \%$ of the protons are inside the micro-spheres and are only accessible to chemical species which are able to diffuse into the polymer matrix. Pöpken et al. [17] reported power law type reaction kinetics and chemical equilibrium of the above reaction using activities instead of mole fractions by performing experiments in a batch reactor.

In this work, methanol (or water) is present in large excess concentration corresponding to different applications mentioned before. The polymer resin is initially saturated with methanol (or water), and therefore, it is assumed that the ion exchange resin in contact with polar solvent (methanol or water) is completely swollen, the active sulfonic acid group is totally dissociated, and the solvated protons are evenly distributed in the polymer phase. This enables the chemical species participating in the reaction to penetrate the network of cross-linked polymer chains easily, and to come in contact with the solvated protons. Therefore, the quasi-homogeneous model can be applied to describe this reaction in this study. However, when the concentration of methanol (or water) decreases, the polymer phase deviates much from the ideal homogenous state; in such a case, an adsorption-based heterogeneous model would be more suitable.

As the reaction is carried out in a large excess of methanol (or water) in this study, the concentration of methanol (or water) can be assumed to remain essentially unchanged in the course of the reaction. Based on the above assumptions, the quasi-homogeneous kinetic models applicable to this work can be written as

$r_{\mathrm{s}}=k_{\mathrm{fs}}\left[q_{\mathrm{A}}-\frac{q_{\mathrm{E}} q_{\mathrm{W}}}{K_{\mathrm{es}}}\right] \quad$ (for the synthesis of MeOAc)

$r_{\mathrm{h}}=k_{\mathrm{bh}}\left[q_{\mathrm{E}}-\frac{q_{\mathrm{A}} q_{\mathrm{M}}}{K_{\mathrm{eh}}}\right] \quad$ (for the hydrolysis of MeOAc)

$r_{\mathrm{r}}=k_{\mathrm{fr}}\left[q_{\mathrm{A}} q_{\mathrm{M}}-\frac{q_{\mathrm{E}}}{K_{\mathrm{er}}}\right] \quad($ for the recovery of acetic acid $)$

where $r$ denotes the reaction rate, $q_{i}$ is the concentration of component $i$ (A, E, M or W) in the polymer phase, $k_{\mathrm{f}}$ and $k_{\mathrm{b}}$ are the forward and backward reaction rate constant respectively, $K_{\mathrm{e}}$ is the reaction equilibrium constant, and the second subscript, $\mathrm{s}$, h or $\mathrm{r}$, stands for synthesis, hydrolysis or recovery. The concentration of the adsorbed component $i$ $\left(q_{i}\right)$ in the polymer phase is computed by assuming that the liquid and polymer phase are in constant equilibrium. One then uses a linear adsorption isotherm (Henry's law), which is expressed as

$q_{i}=K_{i j} C_{i}$

where $K_{i j}$ represents the adsorption equilibrium constant of component $i(\mathrm{~A}, \mathrm{E}, \mathrm{M}$ or $\mathrm{W})$ for the $j$ th application (synthesis, hydrolysis or recovery). The linear adsorption isotherm is only valid when the concentrations of the adsorbed species are dilute in the bulk liquid phase, as is the case in this study. When the concentrations of the reactants and products are not sufficiently low, non-linear adsorption models, such as Langmuir model, should be adopted in order to describe adsorption behavior accurately.

\section{Experimental details}

\subsection{Chemicals}

Methanol (purity >99.9wt.\%) and acetic acid (purity $>99.8$ wt.\%) were obtained from Merck. Methyl acetate (purity >99 wt.\%) was obtained from Riedel-de-Haën. They were used without further purification.

\subsection{Catalyst}

The macro-porous sulfonic ion-exchange acid resin Amberlyst 15 Dry purchased from Rohm and Haas Company was chosen as the catalyst in this work. These are cross-linked three-dimensional structures of polymeric material obtained by sulfonation of a copolymer of polystyrene and divinyl benzene. These resin are heat-sensitive and lose activity above $393 \mathrm{~K}$. Macro-porous resins are better catalysts than micro-porous resins, particularly in non-aqueous media where the latter resins do not swell appreciably. The main properties of the ion exchange resin are listed in Table 1. For the methyl acetate synthesis study in which methanol is used as solvent, the catalyst was dried under vacuum at $363 \mathrm{~K}$ for $8 \mathrm{~h}$ before usage. Drying at higher temperatures runs the risk of losing catalyst capacity due to gradual desulfonation.

\subsection{Experimental set-up}

The experiments were conducted in a $0.25 \mathrm{~m}$ long HPLC column of inner diameter $0.0094 \mathrm{~m}$ packed with Amberlyst 15. The column was immersed in a water bath filled with a 1:1 mixture of ethylene glycol and water, together with a temperature controller to obtain desirable constant temperatures. A binary, series 200 LC pump from Perkin-Elmer 
Table 1

Typical properties of Amberlyst 15 dry ion-exchange resin

\begin{tabular}{ll}
\hline Appearance & Hard, dry, spherical particles \\
Typical particle size distribution & Retained on US standard screens (\%) \\
16 mesh & $2-5$ \\
$16-20$ mesh & $20-30$ \\
$20-30$ mesh & $45-55$ \\
$30-40$ mesh & $15-25$ \\
$40-50$ mesh & $5-10$ \\
Through 50 mesh & 1.0 \\
Bulk density $\left(\mathrm{kg} / \mathrm{m}^{3}\right)$ & 608 \\
Moisture (by weight) & Less than $1 \%$ \\
Hydrogen ion concentration & 4.7 \\
$\quad$ (meq./g dry) & \\
Surface area (m $\left.{ }^{2} / \mathrm{g}\right)$ & 50 \\
Porosity (ml pore $/ \mathrm{ml}$ bead) & 0.36 \\
Average pore diameter $(\AA)$ & 240 \\
\hline
\end{tabular}

was connected to the column to provide a rectangular pulse input of width $t_{\mathrm{p}}$. Effluent from the exit of the column was collected manually at fixed time intervals.

\subsection{Analysis}

A HP 6890 gas chromatography equipped with 7683 Automatic Injector and FID was used to determine the concentration of the liquid samples of methanol, methyl acetate, and acetic acid. A $30 \mathrm{~m} \times 0.53 \mathrm{~mm} \times 1 \mu \mathrm{m} \mathrm{OV}-1$ fused silica capillary column was used to separate the reaction mixture. Water concentration was measured using a volumetric Karl Fischer titrator with model 100-titration controller from Denver Instrument.

\subsection{Experimental procedure}

Experiments were conducted at three different temperatures $(313,318$ and $323 \mathrm{~K})$, feed concentrations and flow rates. The column was washed with mobile phase (methanol or water) until the effluent liquid was colorless to ensure removal of impurities when fresh catalyst was used. In the subsequent runs, the column was washed with methanol (or water) for about $30 \mathrm{~min}$ before feeding. The feed (a rectangular pulse input of width 5-10 min) was introduced to the packed bed reactor by switching on the LC pump connected with the feed reservoir. Afterwards, pure methanol (or water) was continuously fed to the column to wash off the chemicals adsorbed on the catalyst.

Two types of experiments (non-reactive as well as reactive) were carried out in a single column packed bed reactor with either methanol or water as mobile phase at three different temperatures. Adsorption parameters were determined from the non-reactive experiments while kinetic parameters were evaluated from the reactive experiments. When methanol is used as a carrier, a mixture of methyl acetate and water dissolved in methanol is used as feed for the non-reactive breakthrough experiments, while a binary mix- ture of acetic acid and methanol was fed to the column in the reactive breakthrough experiments. When water is used as mobile phase, a binary mixture of methanol (or acetic acid) dissolved in water is used as feed for the non-reactive breakthrough experiments, while for the reactive breakthrough experiments, a mixture of acetic acid and methanol dissolved in water or a binary mixture of methyl acetate and water was fed to the reactor. The elution (breakthrough) profiles of the various components from the exit of the column were monitored continuously. The samples were taken at 2 min intervals from the outlet of the column and the breakthrough curves of components involved in the process were obtained by plotting the concentration of each component with elution time.

\section{Development of mathematical model}

A mathematical model based on a quasi-homogeneous kinetics was developed. The model assumes the reaction in the polymer phase to be homogeneous considering the large excess of methanol (or water) used in the reaction mixture. The behavior of reactants and products in the fixed bed reactor was described by a kinetic model, which assumes that the mobile and the stationary phases are always in equilibrium, and is put forward for convenience in our current studies, which use a simulated countercurrent moving bed chromatographic reactor.

The mass balance equations can be written based on the equilibrium-dispersive model, which assumes that the contributions of all the non-equilibrium effects are lumped into an apparent axial dispersion coefficient, $D$, and the apparent dispersion coefficients of the solutes remain constant, independent of the concentration of the components. Therefore, the mass balance equation of component $i$ for the reactive breakthrough system can be expressed as follows:

$$
\begin{aligned}
& \frac{\partial C_{i}}{\partial t}+\left(\frac{1-\varepsilon}{\varepsilon}\right) \frac{\partial q_{i}}{\partial t}+\frac{u}{\varepsilon} \frac{\partial C_{i}}{\partial z}-\left(\frac{1-\varepsilon}{\varepsilon}\right) v_{i} r_{j} \\
& =D_{i k} \frac{\partial^{2} C_{i}}{\partial z^{2}}
\end{aligned}
$$

The initial and boundary conditions are given by

$C_{i}[t=0]=C_{i}^{0}$

$C_{i}\left\lfloor 0<t<t_{\mathrm{p}}\right\rfloor_{Z=0}=C_{\mathrm{f}, i}$

$C_{i}\left\lfloor t>t_{\mathrm{p}}\right\rfloor_{Z=0}=0$

$\left[\frac{\partial C_{i}(t)}{\partial z}\right]_{Z=0}=0$

where $u$ is the superficial mobile phase velocity, which is assumed to be constant, and the subscripts $i=\mathrm{A}$ (HOAc), $\mathrm{M}(\mathrm{MeOH}), \mathrm{E}(\mathrm{MeOAc})$ or $\mathrm{W}\left(\mathrm{H}_{2} \mathrm{O}\right), j=\mathrm{s}$ (synthesis), $\mathrm{h}$ (hydrolysis) or $\mathrm{r}$ (recovery), and $k=\mathrm{M}$ or $\mathrm{W}$ for mobile phase. Eq. (6) is the overall mass balance equation of each 
component $i$ in a single packed column in which the first two terms denote the unsteady state term in the fluid and solid phase respectively, the third term represents the convective term, the fourth term stands for the reaction term, while the last term designates the diffusion term. In the case of the non-reactive breakthrough system, the fourth term in the mass balance equation was set to zero. The apparent dispersion coefficient, $D_{i k}$, which is related to the HETP for the corresponding compounds by [18]

$D_{i k}=\frac{H_{i} u}{2}=\frac{L u}{2 N_{\mathrm{ap}, i}}$

In linear chromatography, HETP is related to the axial dispersion, adsorption equilibrium and the coefficients of resistance to mass transfer as described by Van Deemter et al. [19]. However, determination of the value of the height equivalent to theoretical plate, $H_{i}$, or the apparent plate number, $N_{\mathrm{ap}, i}$, is a tedious lengthy process. Hence, in this work, $D_{i k}$ values are obtained by fitting the experimental elution profiles for each component to the solution of the above model equations (Eqs. (2)-(10)). Due to experimental limitations, we made an additional assumption that the apparent dispersion coefficient of acetic acid is equal to that of methyl acetate.

The PDE in Eq. (6) together with the initial and boundary conditions (Eqs. (7)-(10)), kinetic equations (Eqs. (2)-(4) and adsorption equilibrium (Eq. (5)) was solved using the Method of Lines. In this technique, the PDE is first discretized in space using the finite difference method (FDM) to convert it into a set of several-coupled ordinary differential equation (ODE)-initial value problems (IVPs). The numerical method of lines combines a numerical method for the IVPs of ODEs and a numerical method for the boundary value problems (BVPs). In this work, the resultant stiff ODEs of the initial value kind was solved using the subroutine DIVPAG (which is based on Gear's method) in the IMSL library. The breakthrough curves predicted by the model describing the concentration profiles of reactants and products are discussed later.

\section{Regression of breakthrough curves}

In order to determine the kinetic and adsorption parameters, an error function was defined as the sum of square deviations of the component concentrations predicted by the model from the experimentally measured values. It is written as

$F(x)=\sum_{i=1}^{n} \sum_{j=1}^{m}\left[C_{i j, \exp }-C_{i j, m}\right]^{2}$

where $C_{i j}$ is the concentration of $i$ th component for $j$ th data point, $\boldsymbol{x}$ is the vector of the parameters tuned, and the subscripts exp and $\mathrm{m}$ denote experimentally measured and model predicted values respectively. Parameters need to be determined by tuning the model predicted values to the experimental breakthrough curves were obtained by minimizing the error function, $F$, using a state-of-the-art optimization technique, the genetic algorithm (GA). GA is a search technique developed by Holland [20] based on the mechanics of natural selection and natural genetics, and has become very popular in recent years because of its superiority over traditional optimization algorithm and its potentiality to solve complex engineering optimization problems. A further understanding of genetic algorithm can be obtained elsewhere [20-22].

\section{Results and discussion}

The first set of experiments was carried out with methanol as mobile phase. Adsorption parameters were determined from the non-reactive experiments, while kinetic parameters were evaluated from the reactive experiments.

\subsection{Determination of adsorption and kinetic parameters with methanol as mobile phase}

The adsorption equilibrium constants and dispersion coefficients of methyl acetate and water were obtained by fitting the non-reactive breakthrough curves predicted by the model to those measured experimentally when a rectangular pulse input of binary mixture of methyl acetate and water dissolved in methanol was fed to the column. The error function $\mathrm{F}$ in Eq. (12) was minimized by tuning four parameters, $\boldsymbol{x}$, namely, $K_{\mathrm{Es}}, K_{\mathrm{Ws}}, D_{\mathrm{EM}}$ and $D_{\mathrm{WM}}$ to match the model predicted values to the experimental breakthrough curves. The single objective function optimization problem involving minimization of the error function was solved using the genetic algorithm. A gene pool of 50 chromosomes was considered and GA operations were carried out for 50 generations, subsequent to which it was observed that all 50 chromosomes converged to a single global optimum point. The CPU time required for 50 generations were about 600 min on the CRAY J916 supercomputer.

Fig. 1 shows the experimental curves as well as the model-predicted breakthrough curves at three different temperature $(313,318$ and $323 \mathrm{~K})$ values. Separation of the two components takes place due to the difference in their affinity towards the adsorbent, and each component elutes from the column at a different time. The figure shows that methyl acetate has less affinity towards the resin than water and there is some band broadening. However, the model predicts quite well the experimentally measured breakthrough curves. The reasons for the broadening are manifold. Mass transfer resistance and axial dispersion are among the most important factors. These were lumped into one parameter, namely, the apparent axial dispersion coefficient, $D_{i j}$. The adsorption and dispersion parameters of methyl acetate and water for the synthesis reaction at different temperatures together with the error function values are given in 

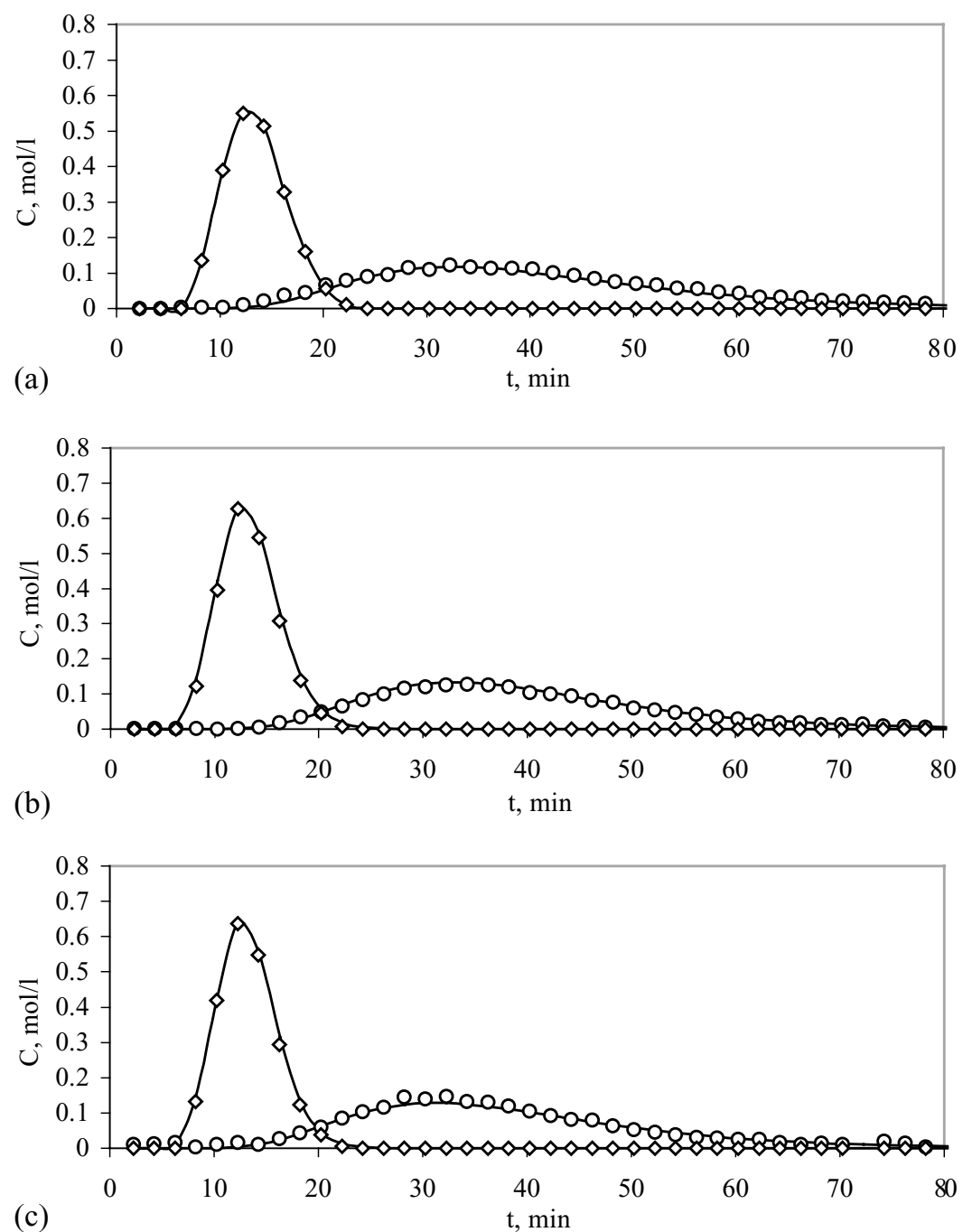

Fig. 1. Effect of temperature on reactive breakthrough curve of the MeOAc- $\mathrm{H}_{2} \mathrm{O}$ system. Symbols: experiment $((\diamond) \mathrm{E} ;(\mathrm{O}) \mathrm{W})$; lines: model prediction. Experimental conditions: $Q=1 \mathrm{ml} / \mathrm{min},[\mathrm{E}]_{\mathrm{f}}=0.89 \mathrm{~mol} / \mathrm{l},[\mathrm{W}]_{\mathrm{f}}=0.81 \mathrm{~mol} / 1, t_{\mathrm{p}}=5 \mathrm{~min}$, solvent: $\mathrm{MeOH}$. (a) $T=313 \mathrm{~K}$, (b) $T=318 \mathrm{~K}$, (c) $T=323 \mathrm{~K}$.

Table 2. The numerical value of adsorption equilibrium constant of water is much greater (seven to eight times) than that of methyl acetate, which is expected since the polarity of water is much stronger than that of methyl acetate towards the resin and is also observed experimentally. Moreover, the calculated adsorption constants of water and methyl acetate decrease with the increase of temperature, which is also expected since adsorption is an exothermic process.

Table 2

Adsorption equilibrium constants and apparent dispersion coefficients for $\mathrm{MeOAc}$ and $\mathrm{H}_{2} \mathrm{O}$ when methanol is used as a mobile phase

\begin{tabular}{llllll}
\hline$T(\mathrm{~K})$ & $K_{\mathrm{Es}}$ & $K_{\mathrm{Ws}}$ & $\begin{array}{l}D_{\mathrm{EM}} \\
\left(\times 10^{6} \mathrm{~m}^{2} / \mathrm{s}\right)\end{array}$ & $\begin{array}{l}D_{\mathrm{WM}} \\
\left(\times 10^{6} \mathrm{~m}^{2} / \mathrm{s}\right)\end{array}$ & $F\left(\mathrm{~mol}^{2} / \mathrm{l}^{2}\right)$ \\
\hline 313 & 0.40 & 3.08 & 5.01 & 14.58 & 0.004 \\
318 & 0.38 & 2.94 & 3.88 & 11.17 & 0.008 \\
323 & 0.36 & 2.78 & 3.46 & 11.03 & 0.013 \\
\hline
\end{tabular}

In order to investigate the validity of the computed parameters, the non-reactive breakthrough experiments were conducted at different total feed compositions. The experimental as well as model-predicted (using the parameter values listed in Table 2) breakthrough curves of methyl acetate and water showed very good agreement when experiments were carried out either at same feed concentration of Fig. 1 but for varying lengths of pulse input $\left(t_{\mathrm{p}}\right)$ or at different feed concentrations [23]. The breakthrough curves calculated by the model were in good agreement with the experimental results for $\mathrm{MeOAc}$. The prediction for $\mathrm{H}_{2} \mathrm{O}$ was not very good due to the tailing effect and possibly a non-linear adsorption isotherm should be used.

In order to investigate the adsorption equilibrium constant of acetic acid $\left(K_{\mathrm{As}}\right)$, the forward reaction rate constant $\left(k_{\mathrm{fs}}\right)$, and the reaction equilibrium constant $\left(K_{\mathrm{es}}\right)$ for the synthesis reaction at three different temperatures (313, 318 and $323 \mathrm{~K}$ ), we conducted reactive breakthrough experiments by using acetic acid dissolved in methanol as a pulse 

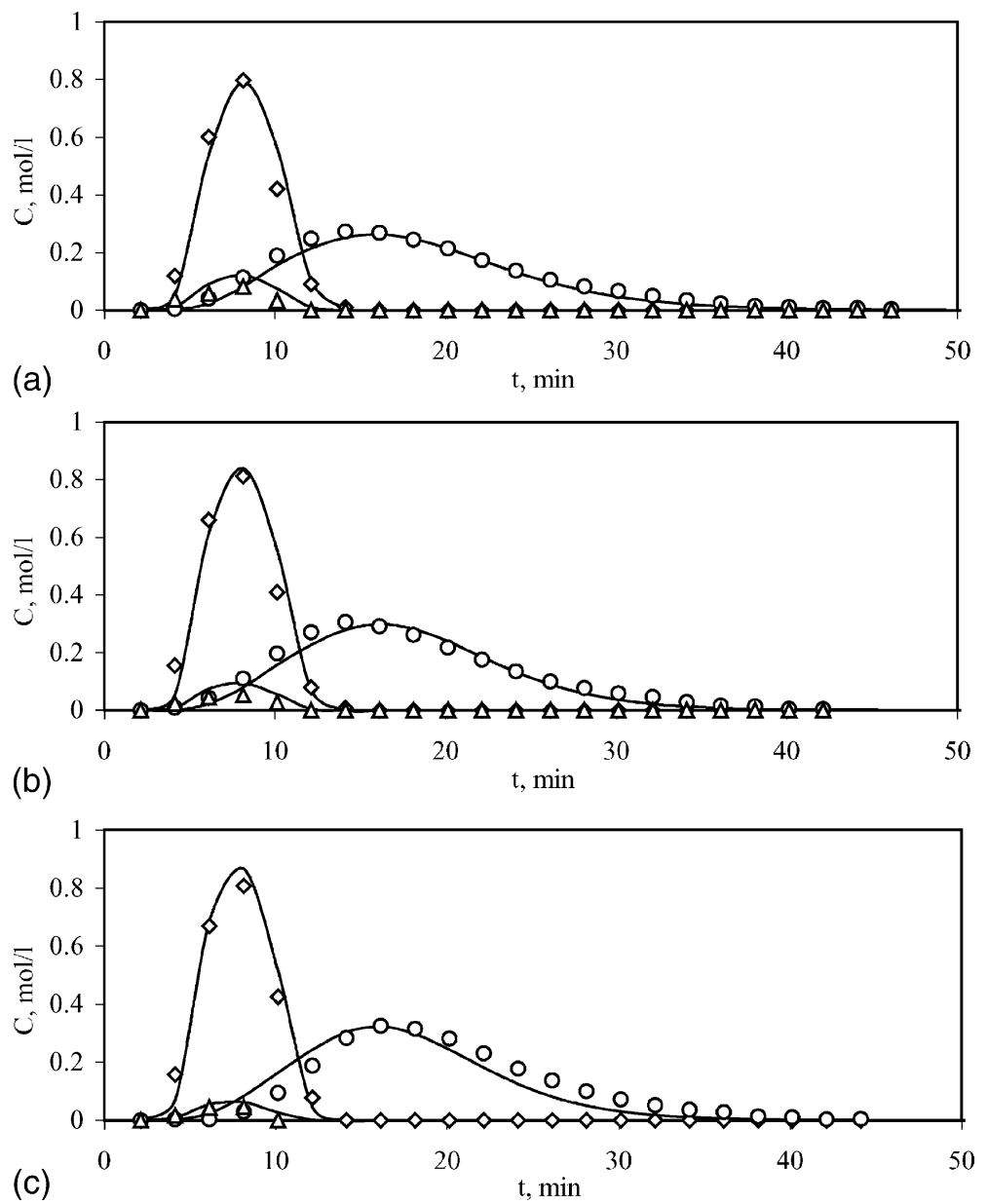

Fig. 2. Effect of temperature on reactive breakthrough curve of the HOAc-MeOAc- $\mathrm{H}_{2} \mathrm{O}$ system. Symbols: experiment $((\triangle) \mathrm{A} ;(\diamond) \mathrm{E} ;(\bigcirc) \mathrm{W})$; lines: model prediction. Experimental conditions: $Q=2 \mathrm{ml} / \mathrm{min},[\mathrm{A}]_{\mathrm{f}}=0.95 \mathrm{~mol} / 1, t_{\mathrm{p}}=5 \mathrm{~min}$, solvent: $\mathrm{MeOH}$. (a) $T=313 \mathrm{~K}$, (b) $T=318 \mathrm{~K}$, (c) $T=323 \mathrm{~K}$.

input. The three parameters $\left(K_{\mathrm{As}}, k_{\mathrm{fs}}, K_{\mathrm{es}}\right)$ were tuned while keeping the other parameters $\left(K_{\mathrm{Ws}}, K_{\mathrm{Es}}, D_{\mathrm{WM}}, D_{\mathrm{EM}}\right)$, determined from the non-reactive breakthrough results, constant at the values listed in Table 2, so that the error function in Eq. (12) is a minimum. Fig. 2 shows the experimental as well as model-predicted results, while the tuned values of the three parameters $\left(K_{\mathrm{As}}, k_{\mathrm{fs}}, K_{\mathrm{es}}\right)$ at different temperatures are listed in Table 3 . The equilibrium conversion of HOAc, and yield and purity of MeOAc for three different temperatures are also reported in Table 3. Once again, the proposed model can predict the experimental breakthrough curves reasonably well.

Table 3

Adsorption equilibrium constant, $K_{\mathrm{As}}$, and kinetic parameters, $k_{\mathrm{fs}}$ and $K_{\mathrm{es}}$ for the synthesis of MeOAc when methanol is used as mobile phase ${ }^{\mathrm{a}}$

\begin{tabular}{llllllll}
\hline$T(\mathrm{~K})$ & $K_{\mathrm{As}}$ & $\begin{array}{l}k_{\mathrm{fs}} \\
\left(\times 10^{2} \mathrm{~s}^{-1}\right)\end{array}$ & $\begin{array}{l}K_{\mathrm{es}} \\
(\mathrm{mol} / \mathrm{l})\end{array}$ & $F\left(\mathrm{~mol}^{2} / \mathrm{l}^{2}\right)$ & $\begin{array}{l}X_{\mathrm{A}} \\
(\%)\end{array}$ & $\begin{array}{l}Y_{\mathrm{E}} \\
(\%)\end{array}$ & $\begin{array}{l}P_{\mathrm{E}} \\
(\%)\end{array}$ \\
\hline 313 & 0.48 & 1.42 & 349 & 0.042 & 98.57 & 98.57 & 49.64 \\
318 & 0.43 & 1.77 & 334 & 0.052 & 98.49 & 98.49 & 49.62 \\
323 & 0.38 & 2.40 & 325 & 0.026 & 98.43 & 98.43 & 49.60
\end{tabular}

${ }^{\text {a }}$ Calculation is based on $[\mathrm{A}]_{0}=2.0 \mathrm{~mol} / \mathrm{l} ; X_{\mathrm{A}}=1-[\mathrm{A}]_{\text {out }} /[\mathrm{A}]_{0}$; $Y_{\mathrm{E}}=[\mathrm{E}]_{\text {out }} /[\mathrm{A}]_{0} ; P_{\mathrm{E}}=[\mathrm{E}]_{\text {out }} /\left([\mathrm{E}]_{\text {out }}+[\mathrm{A}]_{\text {out }}+[\mathrm{W}]_{\text {out }}\right)$.
In the heterogeneous reaction sequence, mass transfer of reactants first takes place from the bulk fluid to the external surface of the pellet. The reactants then diffuse from the external surface into and through the pores within the pellet. In order to determine intrinsic kinetic parameters, the effect of bulk diffusion resistance and pore diffusion resistance must be estimated first.

\subsubsection{Estimation of bulk (external) diffusion resistance}

The Mear's criterion [24], which uses the measured rate of reaction, helps to determine if external diffusion is limiting the reaction. Mear's criterion states that external mass transfer can be neglected if

$\frac{\left(-r_{\mathrm{A}}^{\prime} \rho_{\mathrm{b}}\right) R n}{k_{\mathrm{c}} C_{\mathrm{A}}}<0.15$

where $\left(-r_{\mathrm{A}}^{\prime} \rho_{\mathrm{b}}\right)$ is the measured rate of reaction $\left(\mathrm{mol} / \mathrm{m}^{3} \mathrm{~s}\right)$, $R$ the average radius of catalyst particles $\left(3.75 \times 10^{-4} \mathrm{~m}\right)$, $n$ the order of reaction, $C_{\mathrm{A}}$ the bulk concentration of the reactant $(\mathrm{HOAc})\left(\mathrm{mol} / \mathrm{m}^{3}\right)$, and $k_{\mathrm{c}}$ is the mass transfer coefficient $(\mathrm{m} / \mathrm{s})$. The measured initial rate of reaction can be determined from Eq. (2) as $4.08 \mathrm{~mol} / \mathrm{m}^{3}$-cat bed s, and 
the mass transfer coefficient, $k_{\mathrm{c}}$, can be estimated from Dwidevi-Upadhyay mass transfer correlation [25] as $4.13 \times$ $10^{-5} \mathrm{~m} / \mathrm{s}$, which results in a Mear's criterion parameter value of $3.79 \times 10^{-3}$, which is less than 0.15 . Therefore, bulk diffusion can be neglected. Details of the above calculation are very similar to those reported by Zhang et al. [26] and are not repeated here. It should also be noted that estimated kinetic parameters as reported in Table 3 can predict the breakthrough curves very well when experiments were performed at different flow rates (see later), confirming further that external mass transfer resistance is negligible.

\subsubsection{Estimation of pore diffusion resistance}

The Weisz-Prater criterion is used to determine whether internal mass transfer is limiting the reaction. This Weisz-Prater criterion [27] states that internal pore diffusion is negligible if

$\frac{\left[-r_{\mathrm{A}}^{\prime} \rho_{\mathrm{b}}\right]_{\mathrm{obs}} L^{2}}{D_{\mathrm{e}} C_{\mathrm{As}}}<1$

where $C_{\mathrm{As}}$ is the concentration of HOAc on the resin surface, which can be taken as $C_{\mathrm{A}}\left(=1000 \mathrm{~mol} / \mathrm{m}^{3}\right)$ since bulk diffusion is negligible. $D_{\mathrm{e}}$ is the effective diffusivity of HOAc in $\mathrm{MeOH}$, and is given by $[\varepsilon / \tau] D_{\mathrm{AM}}$, where $\varepsilon$ is particle porosity $(=0.36$, Table 1$), \tau$ is the tortuosity factor taken as 1.3 [27], and $D_{\mathrm{AM}}$ is taken as $5 \times 10^{-6} \mathrm{~m}^{2} / \mathrm{s}$ (Table 2), the same as the value of $D_{\mathrm{EM}}$ stated before. $L$ for a spherical pellet is given by $R / 3$, where $R$ is the average radius $\left(3.75 \times 10^{-4} \mathrm{~m}\right)$ of the resin particles. The Weisz-Prater parameter calculated for the given system yields a value of $4.6 \times 10^{-5}$ signifying that internal pore diffusion is also negligible. Details of the above calculation are very similar to the one reported by Zhang et al. [26] and are not repeated here. To further ascertain that the internal diffusion effect is negligible, we screened commercial Amberlyst 15 into several different particle sizes, and we conducted experiments at $323 \mathrm{~K}$ by using different sieved fractions of the catalyst particles in a batch reactor. Fig. 3 clearly shows no observable effect of particle size on the forward (synthesis) or backward (hydrolysis) reaction kinetics.

The tuned adsorption and kinetic parameters of the three components at three different temperatures were used next to verify the validity of the model by checking whether it can correctly predict experimental reactive breakthrough curves of the three components when experiments were performed at different flow rates and feed concentrations. It was observed that, when adsorption and kinetic parameter values given in Tables 2 and 3 are used, the model could predict quite adequately the experimental breakthrough curves at different flow rates and feed concentrations of all three components. The figures are not shown here for brevity but are available elsewhere [23]. It was observed that, when a reaction occurs, broadening of the elution peaks was less significant, because the overall rate was controlled by kinetics (rate determining step) rather than by axial dispersion. The main reason for the slight error was believed to be due to the fact that we have neglected the varied degree to which the resin gets swollen when concentration changes inside the packed bed reactor. As a result, the local voidage will change, which subsequently changes the interfacial flow velocity. However, considering the low concentration range adopted in this work, the concentration change was relatively small, and the error caused was insignificant.

\subsection{Effect of temperature on the adsorption and kinetic parameters}

The dependence of adsorption constants, $K_{\mathrm{Es}}, K_{\mathrm{Ws}}$ and $K_{\mathrm{As}}$, on temperature can be determined from the equation:

$K_{\text {is }}=K_{i \mathrm{~s}}^{0} \exp \left[-\frac{\Delta H_{\text {is }}}{R T}\right], \quad i=\mathrm{A}, \mathrm{E}$ or $\mathrm{W}$

where $(-\Delta H)$ is the heat of adsorption. The values of $K_{i \mathrm{~s}}^{0}$ and $\left(-\Delta H_{i s}\right)$ were obtained for each component $(\mathrm{E}, \mathrm{W}$ and $\mathrm{A})$ by least squares fit of Eq. (15) to the data reported in Tables 2 and 3 are given in Table 4 . The heat of adsorption $\left(-\Delta H_{i \mathrm{~s}}\right)$

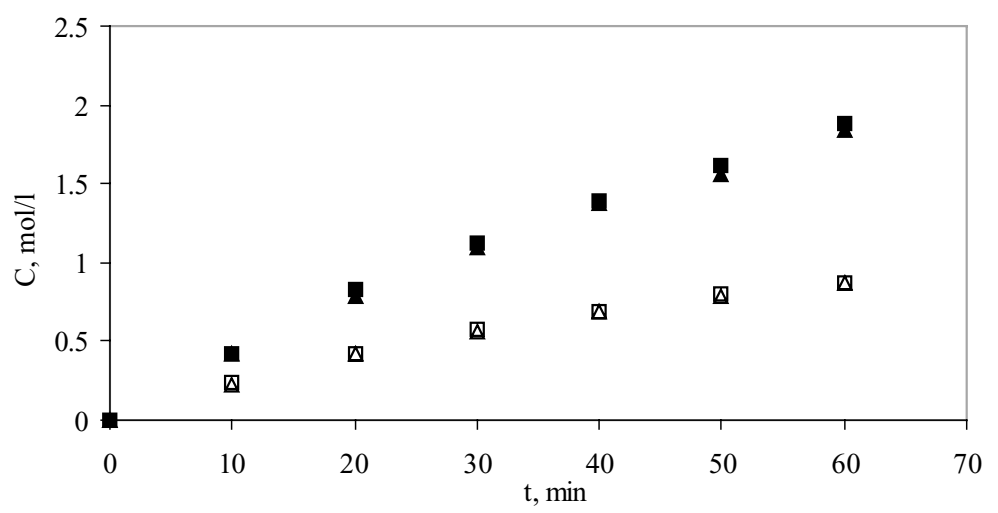

Fig. 3. Effect of particle size on the reaction kinetics of synthesis of MeOAc and hydrolysis reaction. Symbols: $(\square) d=0.42-0.60 \mathrm{~mm}$; $(\triangle)$ $d=0.85-1.00 \mathrm{~mm}$; open symbols: synthesis reaction; closed symbols: hydrolysis reaction. Experimental conditions: $T=323 \mathrm{~K}$; for synthesis reaction: initial molar ratio of $\mathrm{HOAc}: \mathrm{MeOH}=0.25: 4.80$, mass of dry catalyst $=5 \mathrm{~g}$; for hydrolysis reaction: initial molar ratio of $\mathrm{MeOAc}: \mathrm{H}_{2} \mathrm{O}=0.70: 10.50$, mass of dry catalyst $=20 \mathrm{~g}$. $C=[\mathrm{MeOAc}]$ (for synthesis); [HOAc] (for hydrolysis). 
Table 4

Heat of adsorption, heat of reaction, activation energy and other thermodynamic values for the synthesis of MeOAc when methanol is used as mobile phase

\begin{tabular}{|c|c|c|c|c|c|c|c|c|c|}
\hline \multicolumn{3}{|l|}{$\overline{K_{i \mathrm{~s}}^{0}}$} & \multicolumn{3}{|c|}{$-\Delta H_{i \mathrm{~s}}(\mathrm{~kJ} / \mathrm{mol})$} & \multirow{2}{*}{$\begin{array}{l}k_{\mathrm{fs}}^{0}\left(\mathrm{~s}^{-1}\right) \\
\text { (from Eq. (16)) }\end{array}$} & \multirow{2}{*}{$\begin{array}{l}E_{\mathrm{fs}}(\mathrm{kJ} / \mathrm{mol}) \\
\text { (from Eq. (16)) }\end{array}$} & \multirow{2}{*}{$\begin{array}{l}\Delta S_{\mathrm{R}, \mathrm{s}}^{\circ}(\mathrm{J} / \mathrm{mol} \mathrm{K}) \\
\text { (from Eq. (17)) }\end{array}$} & \multirow{2}{*}{$\begin{array}{l}-\Delta H_{\mathrm{R}, \mathrm{s}}^{\circ}(\mathrm{kJ} / \mathrm{mol}) \\
\text { (from Eq. (17)) }\end{array}$} \\
\hline A & $\mathrm{E}$ & W & A & $\mathrm{E}$ & W & & & & \\
\hline $2.53 \times 10^{-4}$ & 0.012 & 0.116 & 19.64 & 9.10 & 8.53 & $3.26 \times 10^{5}$ & 44.2 & 30 & 5.83 \\
\hline
\end{tabular}

was found to be positive as it is an exothermic process; therefore, $K_{i \text { s }}$ decreases with the increase of temperature. It was also observed that the effect of temperature is not significant in the temperature range under study.

The dependence of forward reaction rate constant $k_{\mathrm{fs}}$ on temperature was determined from Arrhenius equation:

$k_{\mathrm{fs}}=k_{\mathrm{fs}}^{0} \exp \left[-\frac{E_{\mathrm{fs}}}{R T}\right]$

The reaction equilibrium constant, $K_{\mathrm{es}}$, is related by

$$
\begin{aligned}
K_{\mathrm{es}} & =\frac{k_{\mathrm{fs}}}{k_{\mathrm{bs}}}=\frac{k_{\mathrm{fs}}^{0}}{k_{\mathrm{bs}}^{0}} \exp \left[-\frac{E_{\mathrm{fs}}-E_{\mathrm{bs}}}{R T}\right]=\exp \left[-\frac{\Delta G_{\mathrm{R}, \mathrm{s}}^{\circ}}{R T}\right] \\
& =\exp \left[\frac{\Delta S_{\mathrm{R}, \mathrm{s}}^{\circ}}{R}\right] \exp \left[-\frac{\Delta H_{\mathrm{R}, \mathrm{s}}^{\circ}}{R T}\right]
\end{aligned}
$$

The values of activation energy, $E_{\mathrm{fs}}$, and pre-exponential factor, $k_{\mathrm{fs}}^{0}$ were obtained from least square fit of Eq. (16) to the data given in Table 3 and the computed values are given in Table 4 . The values of $\Delta S_{\mathrm{R}, \mathrm{s}}^{\circ}[\equiv$ $\left.R \ln \left(k_{\mathrm{fs}}^{0} / k_{\mathrm{bs}}^{0}\right)\right]$ and $\Delta H_{\mathrm{R}, \mathrm{s}}^{\circ}\left[\equiv\left(E_{\mathrm{fs}}-E_{\mathrm{bs}}\right)\right]$ were also obtained by least square fit of Eq. (17) and the values are given in Table 4.

\subsection{Determination of adsorption and kinetic parameters with water as mobile phase}

The non-reactive breakthrough experiments were carried out at three different temperatures $(313,318$, and $323 \mathrm{~K})$ using acetic acid or methanol dissolved in water as a pulse input. The experimental and model-predicted breakthrough curves at these three temperatures are shown in Fig. 4 for methanol. The figure for acetic acid is not shown here for brevity but is available elsewhere [23]. The computed adsorption and dispersion parameters of methanol as well as acetic acid at different temperatures are tabulated in Table 5 and the figures show that the model predicts quite well the experimental results.

Table 5

Adsorption equilibrium constants and apparent dispersion coefficients for $\mathrm{HOAc}$ and $\mathrm{MeOH}$ when water is used as mobile phase

\begin{tabular}{llllll}
\hline$T(\mathrm{~K})$ & $K_{\mathrm{Ar}}$ & $K_{\mathrm{Mr}}$ & $\begin{array}{l}D_{\mathrm{AW}} \\
\left(\times 10^{6} \mathrm{~m}^{2} / \mathrm{s}\right)\end{array}$ & $\begin{array}{l}D_{\mathrm{MW}} \\
\left(\times 10^{6} \mathrm{~m}^{2} / \mathrm{s}\right)\end{array}$ & $F\left(\mathrm{~mol}^{2} / \mathrm{l}^{2}\right)$ \\
\hline 313 & 0.74 & 1.02 & 7.09 & 6.30 & 0.001 \\
318 & 0.72 & 0.96 & 6.11 & 6.49 & 0.005 \\
323 & 0.65 & 0.93 & 6.07 & 6.30 & 0.002 \\
\hline
\end{tabular}

\subsection{Determination of kinetic parameters for recovery of dilute acetic acid from wastewater}

The adsorption constant of methyl acetate, the forward reaction rate constant for conversion of acetic acid to methyl acetate, and the reaction equilibrium constant were obtained by fitting the reactive breakthrough curves predicted by the model to the experimental results when a binary mixture of methanol and acetic acid dissolved in water was fed as pulse input with water as mobile phase. In order to solve the model equations for the reactive breakthrough experiments, the parameters $\left(K_{\mathrm{Mr}}, K_{\mathrm{Ar}}, D_{\mathrm{MW}}, D_{\mathrm{AW}}\right)$ determined from the non-reactive breakthrough experiments (see Table 5) were used together with the assumption that $D_{\text {EW }}$ is equal to $D_{\text {AW }}$. The reactive breakthrough experiments were carried out at three different temperatures (313, 318 , and $323 \mathrm{~K}$ ), and the experimental results were fitted with the model described in Eq. (6) with the kinetic expression given by Eq. (4) by minimizing the error function defined in Eq. (12). The experimental and model-predicted elution profiles at these three temperatures are shown in Fig. 5 while the computed parameters $\left(K_{\mathrm{Er}}, k_{\mathrm{fr}}\right.$ and $\left.K_{\mathrm{er}}\right)$ are listed in Table 6 . Once again the reactive breakthrough experiments were conducted at different flow rates and feed concentrations in order to verify the robustness of the computed parameters. It was found that the model could predict experimental results at different initial concentrations and flow rates for three different temperatures reasonably well [23].

\subsection{Determination of kinetic parameters for the hydrolysis reaction}

The adsorption constant of methyl acetate $\left(K_{\mathrm{Eh}}\right)$, the backward reaction rate constant $\left(k_{\mathrm{bh}}\right)$, and the reaction equilibrium constant $\left(K_{\mathrm{eh}}\right)$ were obtained by fitting the reactive breakthrough curves predicted by the model to the experimental results when methyl acetate dissolved in water was fed as pulse input with water as mobile phase. The parameters $\left(K_{\mathrm{Mr}}, K_{\mathrm{Ar}}, D_{\mathrm{MW}}, D_{\mathrm{AW}}\right)$ determined from

Table 6

Adsorption equilibrium constant, $K_{\mathrm{Er}}$, and kinetic parameters, $k_{\mathrm{fr}}$ and $K_{\mathrm{er}}$ for the recovery of acetic acid when water is used as mobile phase

\begin{tabular}{lllll}
\hline$T(\mathrm{~K})$ & $K_{\text {Er }}$ & $10^{4} k_{\text {fr }}(1 / \mathrm{mol} \mathrm{s})$ & $K_{\text {er }}(1 / \mathrm{mol})$ & $F\left(\mathrm{~mol}^{2} / 1^{2}\right)$ \\
\hline 313 & 0.55 & 1.33 & 0.265 & 0.091 \\
318 & 0.53 & 1.67 & 0.253 & 0.085 \\
323 & 0.50 & 2.33 & 0.248 & 0.080 \\
\hline
\end{tabular}



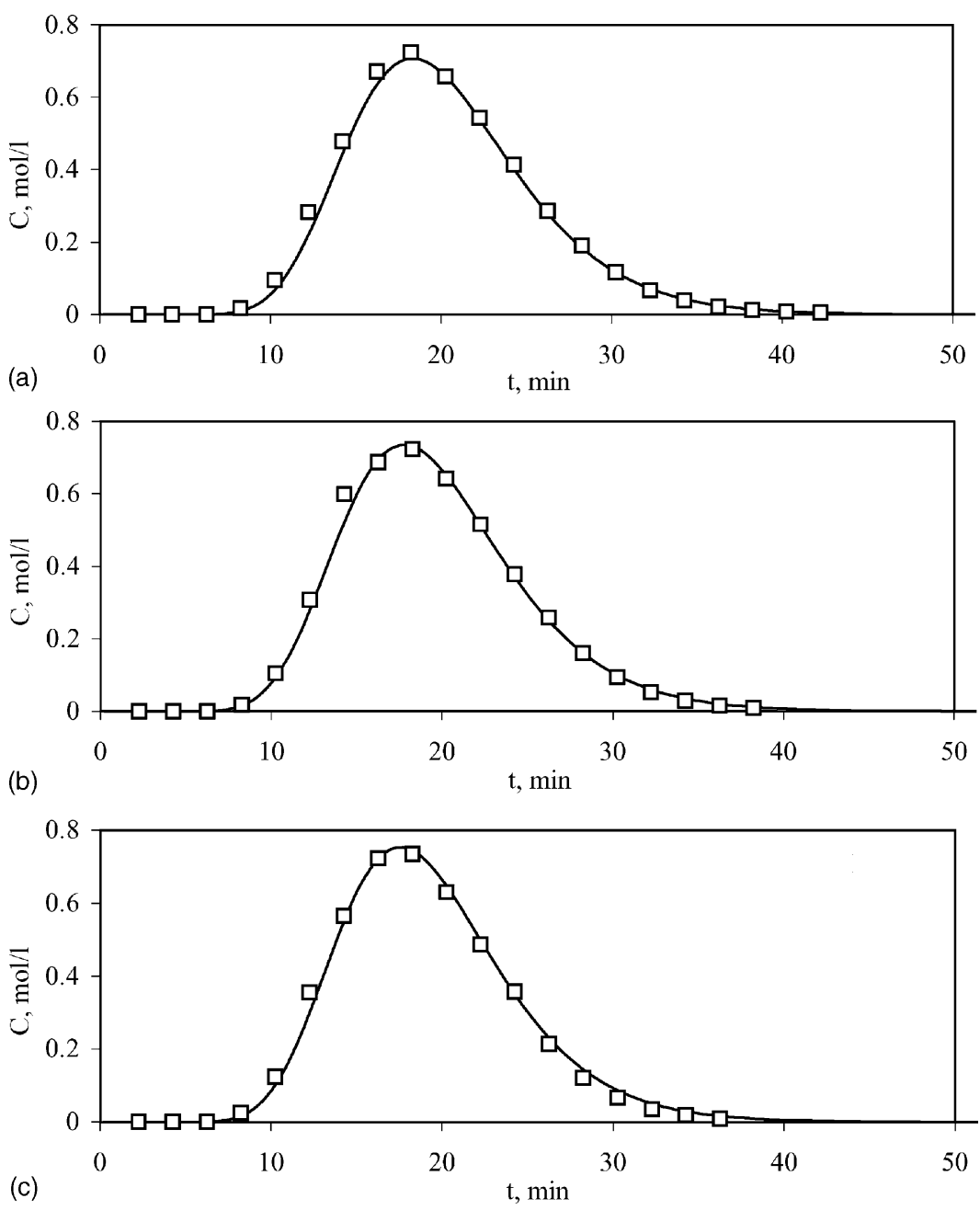

Fig. 4. Effect of temperature on non-reactive breakthrough curve of $\mathrm{MeOH}$. Symbols: experiment; lines: model prediction. Experimental conditions: $Q=1 \mathrm{ml} / \mathrm{min},[\mathrm{M}]_{\mathrm{f}}=1.79 \mathrm{~mol} / 1, t_{\mathrm{p}}=5 \mathrm{~min}$, solvent: water. (a) $T=313 \mathrm{~K}$, (b) $T=318 \mathrm{~K}$, (c) $T=323 \mathrm{~K}$.

the non-reactive breakthrough experiments with water as mobile phase (see Table 5) were used, together with the assumption that $D_{\mathrm{EW}}$ is equal to $D_{\mathrm{AW}}$. The reactive breakthrough experiments were carried out at three different temperatures $(313,318$, and $323 \mathrm{~K})$; the experimental results were fitted with the model described in Eq. (6) with the kinetic expression given by Eq. (3) and minimizing the error function defined in Eq. (12). The experimental and model predicted elution profiles at these three temperatures are shown in Fig. 6, while the computed parameters $\left(K_{\mathrm{Eh}}\right.$, $k_{\text {fh }}$ and $\left.K_{\text {eh }}\right)$ are listed in Table 7 . Once again the reactive breakthrough experiments were conducted at different flow rates and feed concentrations in order to verify the robustness of the computed parameters; it was found that the model could predict experimental results quite well [23].

The adsorption constant of methyl acetate in the hydrolysis reaction, $K_{\mathrm{Eh}}$, is slightly higher than that in the recovery of dilute acetic acid reaction system, namely $K_{\mathrm{Er}}$. This is most likely due to the fact that methyl acetate molecules are more easily accessible to the adsorbent active sites in the hydrolysis of methyl acetate reaction than in the case of recovery of dilute acetate from wastewater. For when methyl acetate was fed to the column in the hydrolysis reaction,

Table 7

Adsorption equilibrium constant, $K_{\mathrm{Eh}}$, and kinetic parameters, $k_{\mathrm{fh}}$ and $K_{\mathrm{eh}}$ for the hydrolysis of methyl acetate when water is used as mobile phase ${ }^{\mathrm{a}}$

\begin{tabular}{llllllll}
\hline$T(\mathrm{~K})$ & $K_{\mathrm{Eh}}$ & $k_{\mathrm{fh}}\left(\times 10^{3} \mathrm{~s}^{-1}\right)$ & $K_{\mathrm{eh}}(\mathrm{mol} / \mathrm{l})$ & $F\left(\mathrm{~mol}^{2} / \mathrm{l}^{2}\right)$ & $X_{\mathrm{E}}(\%)$ & $Y_{\mathrm{M}}(\%)$ & $P_{\mathrm{M}}(\%)$ \\
\hline 313 & 0.705 & 1.25 & 8.89 & 0.025 & 90.25 & 90.25 \\
318 & 0.690 & 1.87 & 9.36 & 0.010 & 91.25 & 91.15 \\
323 & 0.686 & 2.57 & 9.54 & 0.026 & 92.16 & 92.16 & 47.69 \\
\hline
\end{tabular}

${ }^{\text {a }}$ Calculation is based on $[\mathrm{E}]_{0}=1.0 \mathrm{~mol} / \mathrm{l} ; X_{\mathrm{E}}=1-[\mathrm{E}]_{\text {out }} /[\mathrm{E}]_{0} ; Y_{\mathrm{M}}=[\mathrm{M}]_{\text {out }} /[\mathrm{E}]_{0} ; P_{\mathrm{M}}=[\mathrm{M}]_{\text {out }} /\left([\mathrm{E}]_{\text {out }}+[\mathrm{A}]_{\text {out }}+[\mathrm{M}]_{\text {out }}\right)$. 

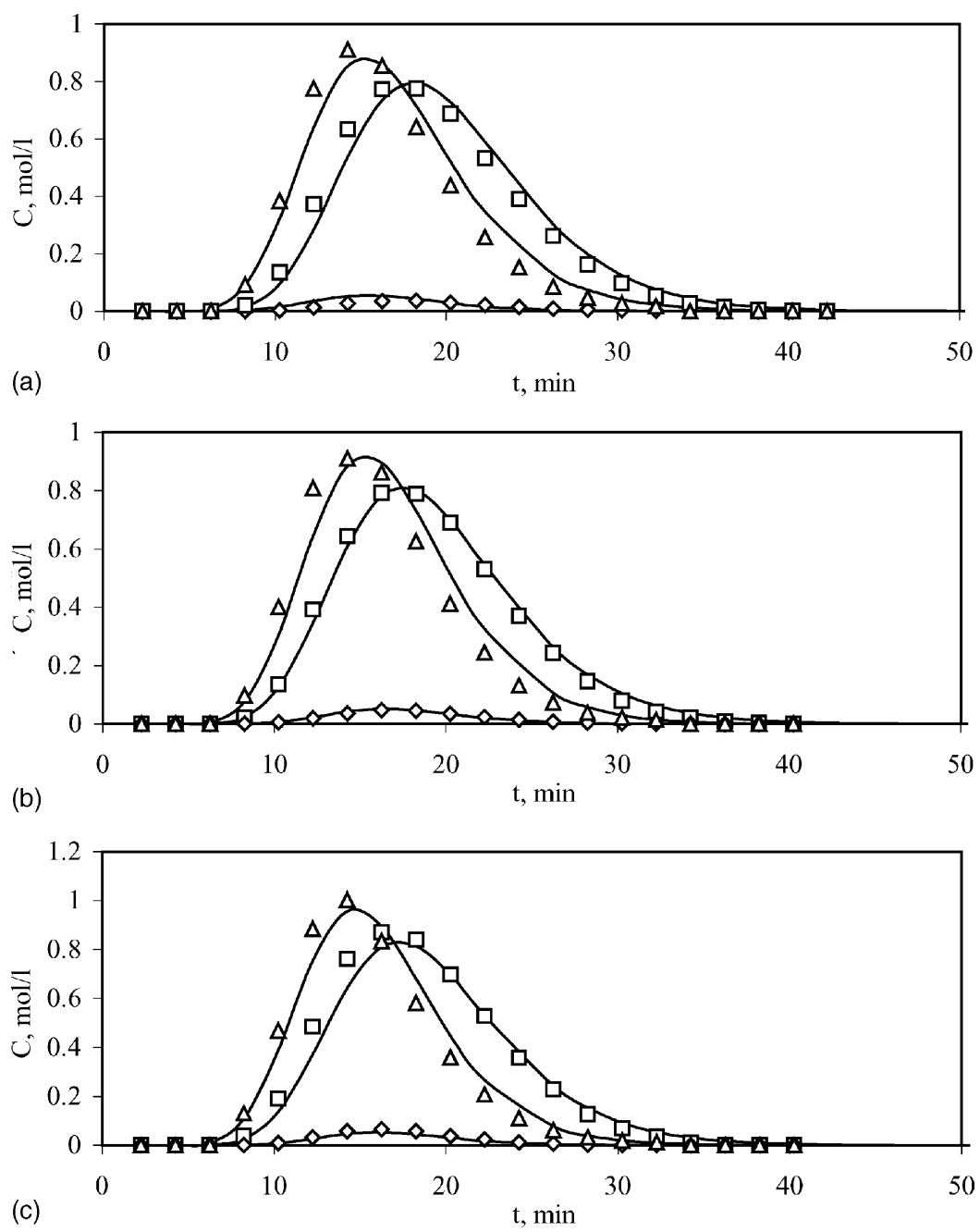

Fig. 5. Effect of temperature on reactive breakthrough curve of the HOAc-MeOH-MeOAc system. Symbols: experiment $((\triangle)$ A; $(\diamond)$ E; $(\square)$ M); lines: model prediction. Experimental conditions: $Q=1 \mathrm{ml} / \mathrm{min},[\mathrm{A}]_{\mathrm{f}}=2.03 \mathrm{~mol} / 1,[\mathrm{M}]_{\mathrm{f}}=2.10 \mathrm{~mol} / 1, t_{\mathrm{p}}=5 \mathrm{~min}$, solvent: water. (a) $T=313 \mathrm{~K}$, (b) $T=318 \mathrm{~K}$, (c) $T=323 \mathrm{~K}$.

there are no other competitive components adsorbed on the catalyst except water. The reaction equilibrium constant of the hydrolysis of methyl acetate increases with the increase of temperature, since the backward reaction is an endothermic process.

\subsection{Effect of temperature on the determined adsorption and kinetic parameters}

The dependence of adsorption constants, $K_{\mathrm{Ah}}, K_{\mathrm{Mh}}, K_{\mathrm{Eh}}$ and $K_{\mathrm{Er}}$, on temperature were determined by a least square fit of Eq. (15) to the data reported in Tables 5-7. The values of $K_{i \mathrm{~h}}^{0},\left(-\Delta H_{\mathrm{ih}}\right), K_{\mathrm{Er}}^{0}$ and $\left(-\Delta H_{\mathrm{Er}}\right)$ are given in Tables 8-9. Once again, the heat of adsorption was found to be positive $\left(-\Delta H_{i}>0\right)$, as it is an exothermic process, and therefore $K_{i \mathrm{~h}}$ and $K_{i \mathrm{r}}$ decrease with the increase of temperature. It was observed that the effect of temperature is also not significant in the temperature range under study for the hydrolysis and recovery reaction. The dependence of reaction rate constant $k_{\mathrm{bh}}$ and $k_{\mathrm{fr}}$ on temperature was determined from the Arrhenius equation (Eq. (16)) and the reaction equilibrium constants, $K_{\mathrm{eh}}$ and $K_{\mathrm{er}}$, were determined from Eq. (17). The values of activation energy, $E_{\mathrm{bh}}$ and $E_{\mathrm{fr}}$, and pre-exponential factor, $k_{\mathrm{bh}}^{0}$ and $k_{\mathrm{fr}}^{0}$ were obtained from the least square fit

Table 8

Heat of adsorption, heat of reaction, activation energy and other thermodynamic values for the hydrolysis of MeOAc when water is used as mobile phase

\begin{tabular}{|c|c|c|c|c|c|c|c|c|c|}
\hline \multicolumn{3}{|l|}{$K_{i \mathrm{~h}}^{0}$} & \multicolumn{3}{|c|}{$-\Delta H_{i \mathrm{~h}}(\mathrm{~kJ} / \mathrm{mol})$} & \multirow{2}{*}{$\begin{array}{l}k_{\mathrm{bh}}^{0}\left(\mathrm{~s}^{-1}\right) \\
\text { (from Eq. (16)) }\end{array}$} & \multirow{2}{*}{$\begin{array}{l}E_{\mathrm{bh}}(\mathrm{kJ} / \mathrm{mol}) \\
\text { (from Eq. (16)) }\end{array}$} & \multirow{2}{*}{$\begin{array}{l}\Delta S_{\mathrm{R}, \mathrm{h}}^{\circ}(\mathrm{J} / \mathrm{mol} \mathrm{K}) \\
\text { (from Eq. (17)) }\end{array}$} & \multirow{2}{*}{$\begin{array}{l}-\Delta H_{\mathrm{R}, \mathrm{h}}^{\circ}(\mathrm{kJ} / \mathrm{mol}) \\
\text { (from Eq. }(17) \text { ) }\end{array}$} \\
\hline A & M & $\mathrm{E}$ & A & $\mathrm{M}$ & $\mathrm{E}$ & & & & \\
\hline 0.0130 & 0.053 & 0.039 & 10.54 & 7.685 & 6.897 & $1.653 \times 10^{7}$ & 60.62 & 37.1 & -5.91 \\
\hline
\end{tabular}



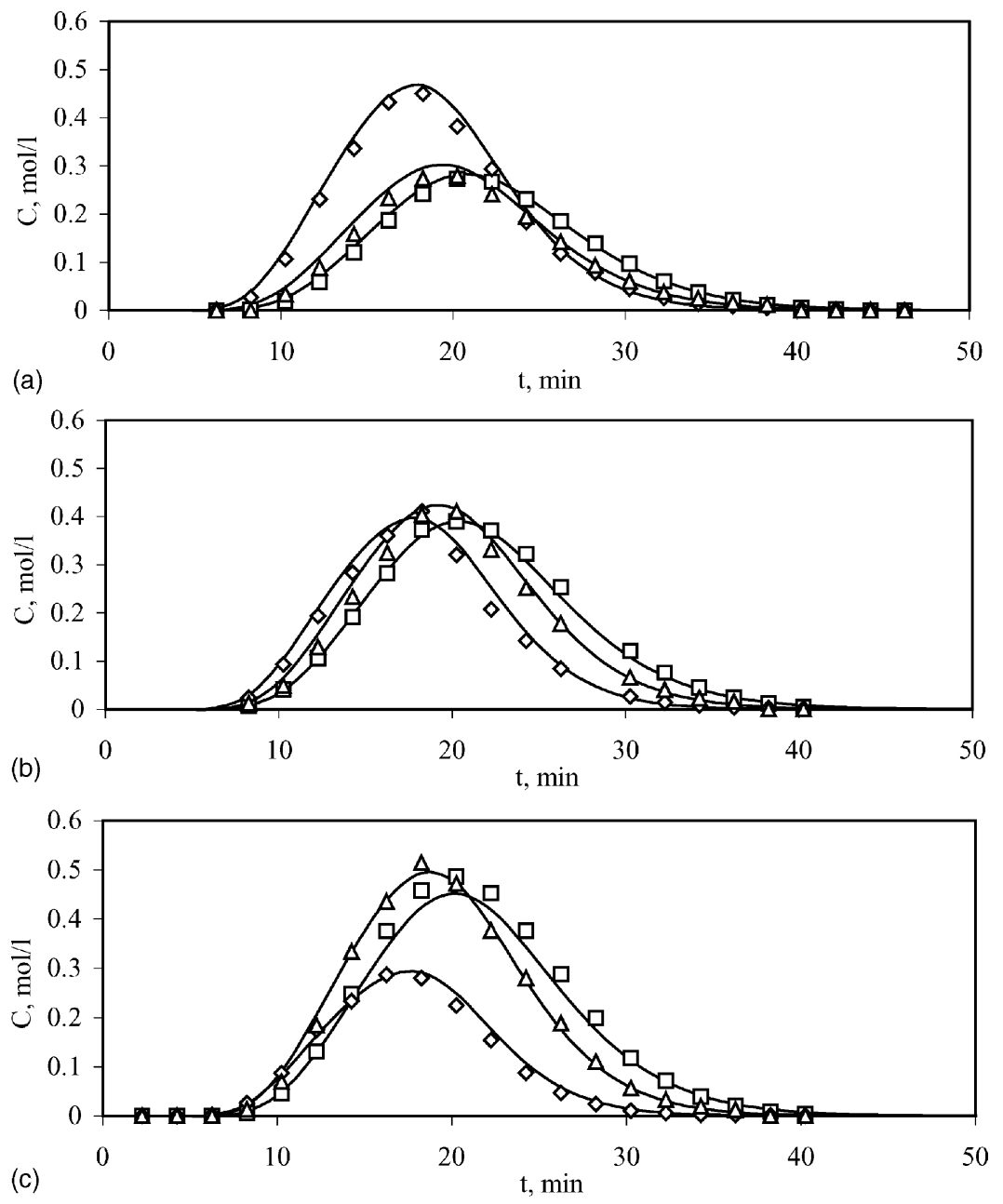

Fig. 6. Effect of temperature on reactive breakthrough curve of the hydrolysis reaction. Symbols: experiment $((\triangle)$ A; $(\diamond)$ E; $(\square)$ M); lines: model prediction. Experimental conditions: $Q=1 \mathrm{ml} / \mathrm{min},[\mathrm{E}]_{\mathrm{f}}=0.99 \mathrm{~mol} / 1, t_{\mathrm{p}}=10 \mathrm{~min}$, solvent: water. (a) $T=313 \mathrm{~K}$, (b) $T=318 \mathrm{~K}$, (c) $T=323 \mathrm{~K}$.

of Eq. (16), while the values of $\Delta S_{\mathrm{R}, \mathrm{h}}^{\circ}, \Delta H_{\mathrm{R}, \mathrm{h}}^{\circ}, \Delta S_{\mathrm{R}, \mathrm{r}}^{\circ}$, and $\Delta H_{\mathrm{R}, \mathrm{r}}^{\circ}$ were obtained by a least square fit of Eq. (17). The values are also given in Tables 8-9.

\subsection{Comparison of the adsorption and kinetic parameters with those reported in literature}

The adsorption and rate parameters calculated in our study do not match well with the results reported in the literature $[16,17]$. In order to find out whether the discrepancy of results are due to use of different types of Amberlyst 15, dry and wet, we carried out a reactive breakthrough experiment to compare the performance of Amberlyst 15 (dry) and Amberlyst 15 (wet). It was found out that there is no significant difference between the two types of Amberlyst 15 when experiments were conducted with wet Amberlyst 15 and that vacuum dried for $10 \mathrm{~h}$ at $353 \mathrm{~K}$.

In order to compare the adsorption equilibrium constants of ours with literature reported values, the optimum values of dispersion coefficients for the literature reported adsorption constants were first obtained by fitting the non-reactive experimental breakthrough curves with our model using genetic algorithm. Table 10 compares the adsorption equilibrium constants reported in the literature with those obtained in this work together with the computed optimum dispersion coefficients. In our computed values, the adsorption constant of water was found to be about 7.7 times greater than that of methyl acetate and 6.4 times greater than that of acetic

Table 9

Heat of adsorption, heat of reaction, activation energy and other thermodynamic values for the recovery of HOAc when water is used as mobile phase

\begin{tabular}{llllll}
\hline$K_{\mathrm{Er}}^{0}$ & $-\Delta H_{\mathrm{er}}(\mathrm{kJ} / \mathrm{mol})$ & $k_{\mathrm{fr}}^{0}(1 / \mathrm{mol} \mathrm{s})$ & $E_{\mathrm{fr}}(\mathrm{kJ} / \mathrm{mol})$ & $\Delta S_{\mathrm{R}, \mathrm{r}}^{\circ}(\mathrm{J} / \mathrm{mol} \mathrm{K})$ & $-\Delta H_{\mathrm{R}, \mathrm{r}}^{\circ}(\mathrm{kJ} / \mathrm{mol})$ \\
\hline 0.29 & 2.303 & $9.386 \times 10^{3}$ & 47.1 & -28.92 & 5.58
\end{tabular}


Table 10

Comparison of the computed adsorption equilibrium constants reported in the literature with those obtained in this study at $T=313 \mathrm{~K}$

\begin{tabular}{lccr}
\hline Parameters & Song et al. [16] & Pöpken et al. [17] & This work \\
\hline$K_{\text {Es }}$ & 0.82 & 4.15 & 0.40 \\
$K_{\text {Ws }}$ & 10.50 & 5.24 & 3.08 \\
$K_{\text {As }}(3.18$ & 3.15 & 0.48 \\
$D_{\text {EM }}\left(\times 10^{6} \mathrm{~m}^{2} / \mathrm{s}\right)$ & 23.52 & 166.59 & 5.01 \\
$D_{\text {WM }}\left(\times 10^{6} \mathrm{~m}^{2} / \mathrm{s}\right)$ & 166.7 & 53.22 & 14.58 \\
\hline
\end{tabular}

acid. All our experimental studies showed that methyl acetate and acetic acid have very similar affinity towards the resin, while water strongly adsorbs on resin. However, the reported adsorption equilibrium values of Pöpken et al. [17] reveal that the values of all three components are of similar magnitudes while Song et al. [16] state that the adsorption constant of acetic acid is 3.9 times that of the methyl acetate. Fig. 7 shows the comparison of the model predictions of our experimental results with our model using three different sets of parameter values listed in Table 10. The figure clearly shows that the model predicted breakthrough curves using the adsorption constants in literature are not in good agreement with the experimental results.

It is not possible to compare directly the kinetic parameters obtained in this work with that of Pöpken et al. [17] due to the use of two different kinetic models. Pöpken et al. [17] reported their results based on a batch reactor while our experimental study is based on a plug flow reactor. In order to compare the adsorption and kinetic parameters obtained in this study from the plug flow reactor experiments with the batch reactor experimental results reported by Pöpken et al. [17], two representative kinetic experiments of Pöpken et al. [17], run number 32 and 42 (see Table 8 of [17]), were repeated by us in a batch reactor. Fig. 8 compares the experimental results obtained by us with the experimental results reported by them [17], together with our model-predicted results. The figure shows that our kinetic model with the kinetic parameters obtained from a packed bed plug flow reactor can predict the experimental acetic acid concentration profile from a batch reactor reasonably well. Hence, the computed adsorption and kinetic parameters obtained from the model described in this work could predict both batch and plug flow reactor experimental elution curves.
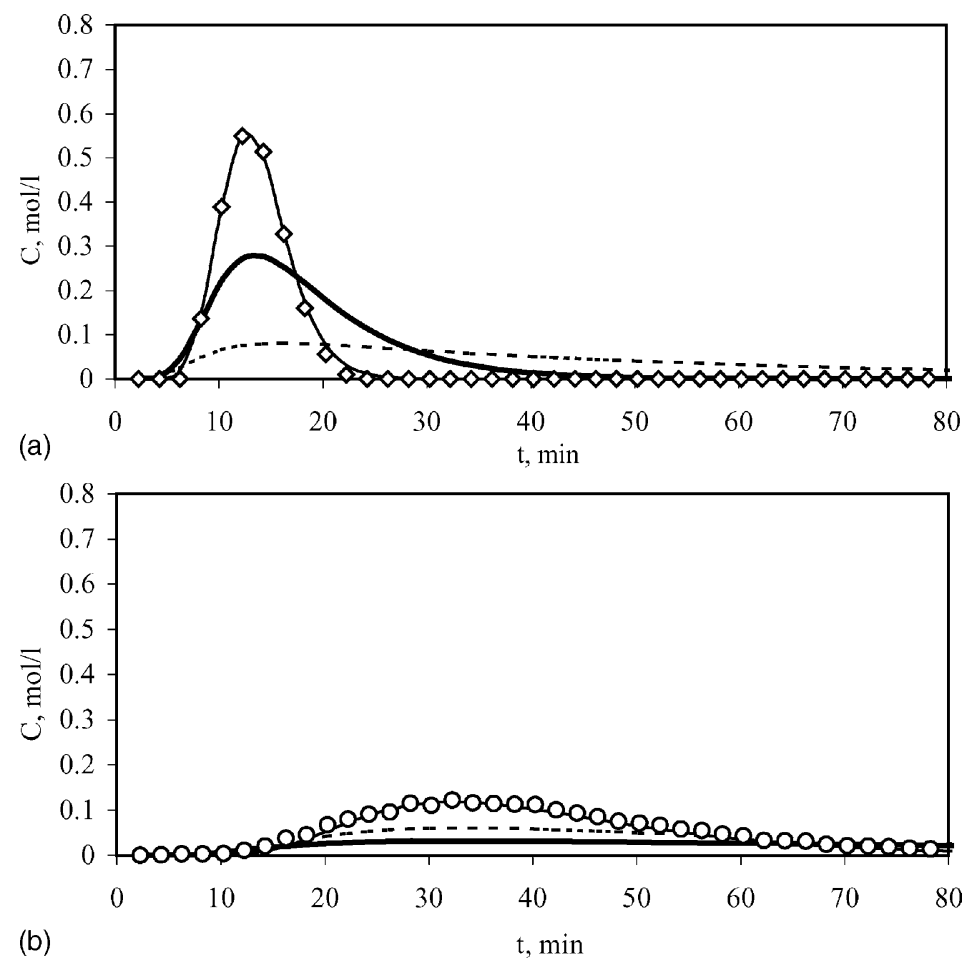

Fig. 7. Comparison of model predicted results with experimental results for non-reactive breakthrough curves of (a) $\mathrm{MeOAc}$ and (b) $\mathrm{H}_{2} \mathrm{O}$. Symbols: experiment $((\diamond)$ E; $(\bigcirc) \mathrm{W})$; lines: model prediction (normal line: this work; bold line: Song et al. [16]; dotted line: Pöpken et al. [17]). Experimental conditions: $Q=1 \mathrm{ml} / \mathrm{min}, T=313 \mathrm{~K}, t_{\mathrm{p}}=5 \mathrm{~min}$, solvent: $\mathrm{MeOH}$. (a) $[\mathrm{E}]_{\mathrm{f}}=0.89 \mathrm{~mol} / \mathrm{l}$, (b) $[\mathrm{W}]_{\mathrm{f}}=0.81 \mathrm{~mol} / \mathrm{l}$. 

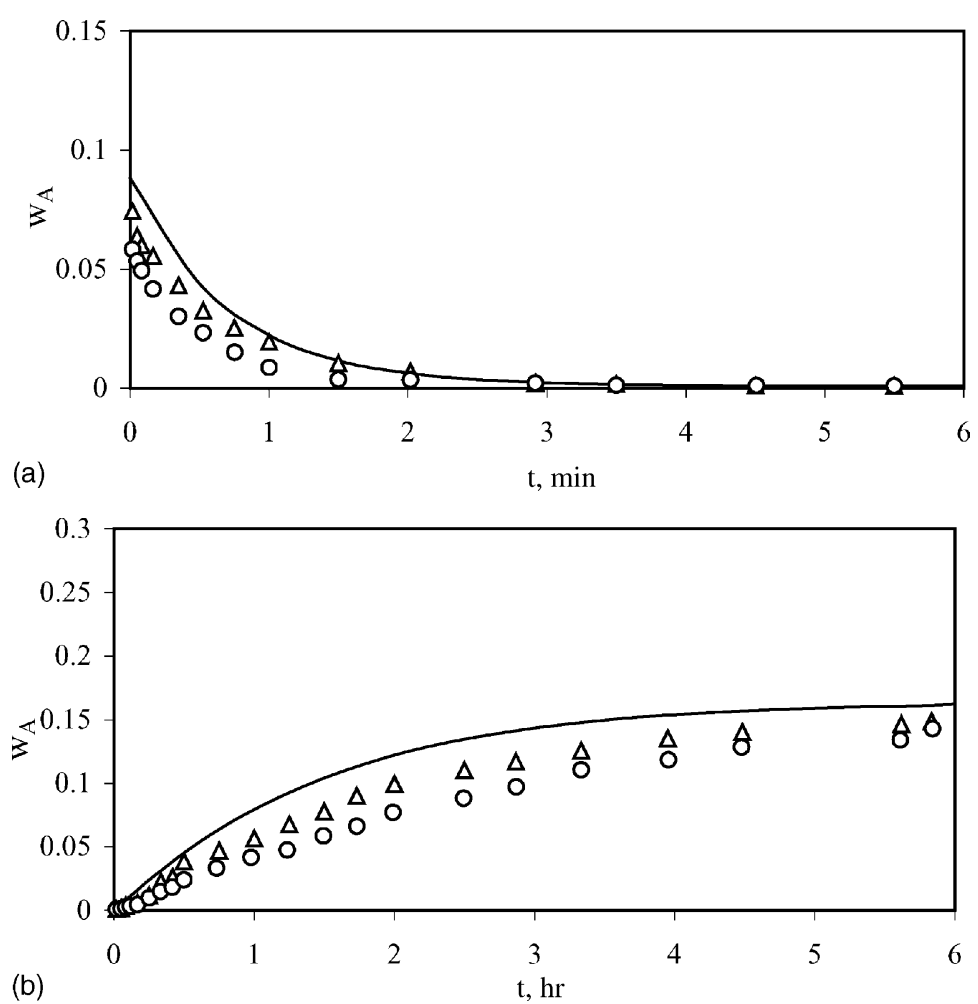

Fig. 8. Comparison of experimental results of HOAc elution profile reported by Pöpken et al. [17] with our experimental and model predicted results in a batch reactor. Symbols: experiment $((\triangle)$ this work; $(\bigcirc)$ Pöpken et al. [17]); lines: our model prediction. Experimental conditions: (a) synthesis reaction, $T=323 \mathrm{~K}$, mass of dry catalyst, $W=5.02 \mathrm{~g}$, initial molar ratio of HOAc:MeOH $=0.25: 4.76$; (b) hydrolysis reaction, $T=318 \mathrm{~K}$, mass of dry catalyst, $W=20.73 \mathrm{~g}$, initial molar ratio of MeOAc: $\mathrm{H}_{2} \mathrm{O}=0.90: 9.36$.

\section{Conclusions}

Reliable adsorption and kinetic parameters are very important for the design of reactors. In this work, the adsorption equilibrium constants, dispersion coefficients and kinetic parameters were obtained for the three different applications of the reversible reaction of acetic acid and methanol catalyzed by Amberlyst 15 ion exchange resins, namely, the synthesis of methyl acetate, the recovery of dilute acetic acid from wastewater, and the hydrolysis of methyl acetate. The quasi-homogeneous kinetic model and linear adsorption isotherm are applicable in this study, since the solvent, methanol or water is present at a large excess concentration. A mathematic model was developed to predict the elution profiles of the components in breakthrough experiments. The breakthrough curves of the reactants and products were experimentally measured at different temperatures, feed concentrations and flow rates. The adsorption and kinetic parameters together with their dependence on temperature were determined by minimizing an error function in order to fit the experimental results with the model-predicted values using a state-of-the-art optimization technique, genetic algorithm. Pure kinetic parameters were obtained, as it was found that, under the experimental conditions used, both external and internal mass resistances are negligible. The accuracy of the proposed mathematical model was further verified when it was observed that the model could predict experimental results at different feed concentrations and flow rates quite well. It was found that, with the increase of temperature, adsorption constants decrease, both the forward and backward reaction rate constants increase, and the reaction equilibrium constants for the forward reaction decrease while that for the backward reactions increase. The computed adsorption and kinetic parameters were also compared with those reported in the literature. It was found that the breakthrough curves predicted using the adsorption and kinetic constants reported in literature from batch reactor study could not predict our experimental results from packed bed plug flow reactor. However, our computed parameters obtained from a packed bed reactor can predict the experimental concentration profiles from a batch reactor reasonably well.

\section{References}

[1] V.H. Agreda, L.R. Partin, W.H. Heise, Chem. Eng. Prog. 86 (2) (1990) 40.

[2] F. Lode, M. Houmard, C. Migliorini, M. Mazzotti, M. Morbidelli, Chem. Eng. Sci. 56 (2) (2001) 269.

[3] Y. Fuchigami, J. Chem. Eng. Jpn. 23 (1990) 354.

[4] S.J. Han, Y. Jin, Z.Q. Yu, Chem. Eng. J. 66 (1997) 227.

[5] R. Neumann, Y. Sasson, Ind. Eng. Chem. Process Des. Dev. 23 (1983) 654. 
[6] Z.P. Xu, K.T. Chuang, Can. J. Chem. Eng. 74 (1996) 493.

[7] J.L. DeGarmo, V.N. Parulekar, V. Pinjala, Chem. Eng. Prog. 88 (3) (1992) 43.

[8] M.F. Doherty, G. Buzad, Trans. Inst. Chem. Eng. 70A (1992) 448.

[9] E. Rev, Ind. Eng. Chem. Res. 33 (9) (1994) 2174

[10] A. Ray, A.L. Tonkovich, R. Aris, R.W. Carr, Chem. Eng. Sci. 45 (8) (1990) 2431.

[11] A.K. Ray, R.W. Carr, R. Aris, Chem. Eng. Sci. 49 (4) (1994) 469.

[12] A.K. Ray, R.W. Carr, Chem. Eng. Sci. 50 (14) (1995) 2195.

[13] M. Mazzotti, A. Kruglov, B. Neri, D. Gelosa, M. Morbidelli, Chem. Eng. Sci. 51 (10) (1996) 1827.

[14] M. Kawase, T. Suzuki, K. Inoue, K. Yoshimoto, K. Hashimoto, Chem. Eng. Sci. 51 (11) (1996) 2971.

[15] M. Kawase, Y. Inoue, T. Araki, K. Hashimoto, Catal. Today 48 (1999) 199.

[16] W. Song, G. Venimadhavan, J.M. Manning, M.F. Malone, M.F. Doherty, Ind. Eng. Chem. Res. 37 (1998) 1917.

[17] T. Pöpken, L. Götze, J. Gmehling, Ind. Eng. Chem. Res. 39 (2000) 2601.
[18] G. Guiochon, S. G. Shirazi, A.M. Katti, Fundamentals of Preparative and Nonlinear Chromatography, Academic Press, Boston, 1994.

[19] J.J. Van Deemter, F.J. Zuiderweg, A. Klinkenberg, Chem. Eng. Sci. 5 (1956) 271

[20] J. H. Holland, Adaptation in Natural and Artificial Systems, University of Michigan Press, Ann Arbor, MI, 1975.

[21] D. E. Goldberg, Genetic Algorithms in Search, Optimization and Machine Learning, Addison-Wesley, Reading, MA, 1989.

[22] V. Bhaskar, S.K. Gupta, A.K. Ray, Rev. Chem. Eng. 16 (1) (2000) 1.

[23] W. Yu, A comprehensive study of esterification and hydrolysis of methyl acetate in simulated moving bed systems, Ph.D. Thesis, National University of Singapore, Singapore, 2003.

[24] D.F. Mear's, Ind. Eng. Chem. Process Des. Dev. 10 (1971) 541.

[25] P.N. Dwidevi, S.N. Upadhyay, Ind. Eng. Chem. Process Des. Dev. 16 (1977) 157.

[26] Z. Zhang, K. Hidajat, A.K. Ray, J. Catal. 200 (2001) 209.

[27] H.C. Fogler, Elements of Chemical Reaction Engineering, Prentice-Hall, Englewood Cliffs, NJ, 1986. 